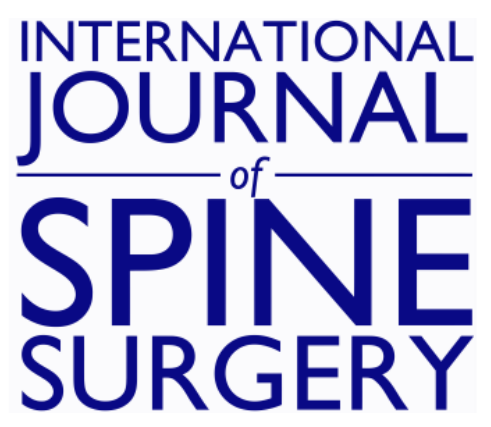

\title{
The Reverse Thomas Position for Thoracolumbar Fracture Height Restoration: Relative Contribution of Patient Positioning in Percutaneous Balloon Kyphoplasty for Acute Vertebral Compressions
}

Jonathan P. Ng, Derek T. Cawley, Suzanne M. Beecher, Joseph F. Baker and John P. McCabe

Int J Spine Surg 2016, 10 ()

doi: https://doi.org/10.14444/3021

http://ijssurgery.com/content/10/21

This information is current as of April 26, 2023.

Email Alerts Receive free email-alerts when new articles cite this article. Sign up at:

http://ijssurgery.com/alerts

The International Journal of Sping Surgerthttp://ijssurgery.com/ by guest on April 26, 2C 2397 Waterbury Circle, Suite 1,

Aurora, IL 60504, Phone: +1-630-375-1432

(C) 2016 ISASS. All Rights Reserved. 


\section{The Reverse Thomas Position for Thoracolumbar Fracture Height Restoration: Relative Contribution of Patient Positioning in Percutaneous Balloon Kyphoplasty for Acute Vertebral Compressions}

Jonathan P. Ng, Derek T. Cawley, Suzanne M. Beecher, Joseph F. Baker, John P. McCabe

Department of Orthopaedic and Traumatology, Galway University Hospital, Republic of Ireland

\section{Abstract}

\section{Background}

Standard positioning for percutaneous balloon kyphoplasty requires placing a patient prone with supports under the iliac crests and upper thorax. The authors believe that hip hyperextension maximises pelvic anteversion creating anterior longitudinal ligamentotaxis, thus facilitating restoration of vertebral height.

\section{Methods}

Radiographic imaging including pre-operative, post-positioning, post balloon tamp inflation and post-operative lateral radiographs were analysed for anterior and posterior column height, wedge angle of the affected vertebra and 3-level Cobb angle in patients with recent fractures of T11-L1. Fracture dimensions of the index vertebra were expressed as percentage of the analogous dimension of the referent vertebra.

\section{Results}

From a total of 149 patients, a full imaging sequence was available on 21 cases of vertebral compression fractures. The described positioning technique created a mean anterior column height increase from $68.3 \%$ to $75.3 \%$ with positioning $(\mathrm{p}=0.15)$, increasing to $82.3 \%$ post balloon inflation. Average Cobb and wedge angle improvement of $4.7^{\circ}$ $(\mathrm{p}=0.004)$ and $3.6^{\circ}(\mathrm{p}=0.002)$ from positioning along were also recorded.

\section{Conclusion}

The Reverse Thomas Position is a safe and effective technique for augmenting thoracolumbar fracture height restoration in percutaneous balloon kyphoplasty.

KEYWORDS: THORACOLUMBAR FRACTURE, PATIENT POSITIONING, PERCUTANEOUS BALLOON KYPHOPLASTY

\section{Introduction}

Percutaneous balloon kyphoplasty $(\mathrm{PBK})$ is a type of percutaneous vertebroplasty that involves fixation of the fractured vertebrae with polymethylmethacrylate (PMMA) after vertebral endplate elevation by a percutaneous inflatable balloon tamp. ${ }^{1}$ Previous studies have demonstrated comparable clinical outcomes to open surgery and conservative management ${ }^{2,3}$ for the treatment of vertebral compression fractures (VCFs). Restoration of vertebral height and correction of kyphotic deformity by $\mathrm{PBK}$ are believed to alleviate biomechanical consequences of $\mathrm{VCFs},{ }^{4}$ thereby reducing fracture-related pain.
In addition to the endplate elevation achieved by the balloon tamp in PBK, some studies have also described significant height recovery and sagittal alignment with appropriate patient positioning. ${ }^{4,5,6,7}$ This is possible due to the dynamic mobility of VCFs. In a radiographic series, McKiernan et al. demonstrated this property in $44 \%$ of patients, with an average anterior vertebral height increase of $106 \%$ of initial fracture. ${ }^{4}$ The phenomenon of dynamic mobility holds particularly true for fractures at the thoracolumbar junction, as this spinal segment bears the greatest dynamic load, which translates to a greater degree of mobility. ${ }^{4}$ Furthermore, there have been several studies describing the optimal patient positioning during kyphoplasty to maximise vertebral height restoration 
prior to balloon inflation and cement injection. Placing the patient in a prone position with or without chest and pelvic bolsters are common techniques described by previous studies. ${ }^{8,9}$ Furthermore, Cawley et al. described using pillow supports anterior to the thigh to hyperextend the hips. ${ }^{10}$ Thus, in contrast to the better-known "Thomas test" for hip flexion contracture, the authors describe locking the hips at maximal extension. This "Reverse Thomas Position" anteriorly rotates the pelvis to maximise lumbar lordosis and enables subsequent anterior longitudinal ligamentotaxis. Therefore, the aim of the study was to determine the efficacy of this described positioning technique in restoration vertebral sagittal alignment in thoracolumbar VCFs.

\section{Materials and Methods}

A retrospective search through the operative database identified 149 consecutive cases of PBK in 160 patients from 2007 to 2014 performed by four orthopaedic surgeons in a single institution. The location of the involved vertebra, mechanism of fracture, time interval between fracture (estimated by date of original radiograph) and procedure, and duration of follow up were recorded.

\section{Selection Criteria}

Inclusion criteria for the study included fractures at thoracolumbar junction (i.e. T11, T12 or L1), and fractures in which preoperative, intraoperative and postoperative radiographs were available. We excluded cases where the index vertebra was not centred on the lateral view and the cranial or caudal vertebrae were not visualised entirely, making the measurements impossible. Those who underwent instrumentation as well as kyphoplasty were also excluded. Moreover, poor quality radiographs without clear outlines were also excluded.

Population

Of 149 consecutive cases of kyphoplasties, $21 \mathrm{VCFs}$ (20 patients) met the eligibility criteria ( 7 males and 13 females). The mean patient age was 54.5 (range, 27 to 90 years). Trauma was the most common causes in our patient series $(61.9 \%, \mathrm{n}=13)$. The majority of fractures occurred at L1 $(42.9 \%, \mathrm{n}=9)$ (Table 1$)$.
Assessment of kyphosis and vertebral body height Digital radiographs of the vertebral bodies were reviewed using the digital radiology imaging system (IPAX RIS, Agfa-Gaevert, Mortsel, Belgium). Preoperatively, erect standardised radiographs were used with lateral views centred on the fractured (index) vertebra. Similarly, intra-operative biplane fluoroscopic radiographs were also analysed, focusing particularly on films taken after patient positioning, and on inflation of balloon. The most recent follow-up standing lateral radiograph was also reviewed. Radiographs were scaled to dimensions of the original preoperative radiograph to minimise interradiographic magnification error.

At each of the four time points, lateral views of the index vertebra were individually examined for changes in vertebral height and sagittal configuration. Vertebral body height was measured to the nearest millimetre. The reference height was taken from an average of the adjacent cranial and caudal normal vertebrae without collapse. The anterior and posterior height losses were presented as percentages of the 'original height' (i.e. reference height) (Figure 1). Each vertebral height was measured on two separate

\begin{tabular}{l}
$\begin{array}{l}\text { Table 1. Demographic details of } 26 \text { vertebral compression fractures in } 25 \\
\text { patients. }\end{array}$ \\
\hline \multicolumn{1}{|c|}{ Demographic Variables } \\
\hline Gender
\end{tabular}


occasions by two independent examiners and an average was calculated.

A three level Cobb angle (kyphosis angle) was determined by using the Cobb method ${ }^{11}$ on a standard radiograph by measuring the angle between the superior endplate of the vertebra above and the inferior endplate of the vertebrae below (Figure 1). A positive angle denoted an overall kyphosis and a negative angle indicated an overall lordosis of the segment measured.

Lastly, the wedge angle was determined as the angle between the superior and inferior endplates of the collapsed index vertebral body ${ }^{11}$ (Figure 1).

Measurements were taken by three interpreters (JPN, SMB, DTC) and the values were compared to identify any discrepancies of more than 2 degrees or $5 \mathrm{~mm}$. Whilst inter- and intra-observer reliability in

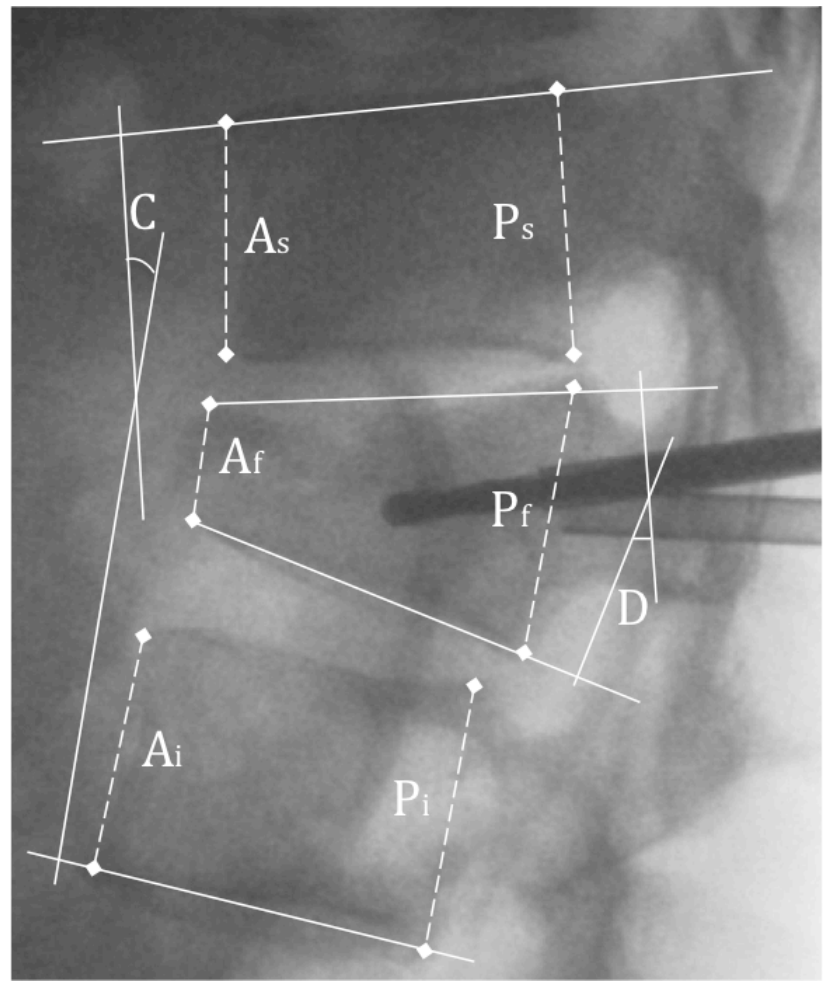

Fig. 1. Intraoperative fluoroscopic screening after patient positioning and prior to balloon inflation. Percentage anterior $(A)$ height loss $=\{1-A f /[(A s$ $+\mathrm{Ai}) / 2]\} \times 100$; and percentage posterior $(\mathrm{P})$ height loss $=\{1-\mathrm{Pf} /[(\mathrm{Ps}+$ $\mathrm{Pi}) / 2]\} \times 100$. (C) The Cobb angle is calculated form the superior endplate of the vertebra above and the inferior endplate of the vertebrae below the fracture vertebra. In cases where two consecutive levels were fractured, a four-level Cobb angle was calculated. (D) The wedge angle was determined as the angle between the superior and inferior endplates of the collapsed index vertebral body. the measurements were not performed, the films were reviewed to reconcile any discrepancies to the final measurements.

\section{Technique}

Postural reduction was achieved by placing patient in prone position on a four-poster frame with a radiolucent base. Foam bolsters were positioned on the anterior aspect of the iliac crest and either side of the upper thorax to allow gravity-assisted vertebral extension. The arms abducted and flexed at shoulder joint with forearms resting on either side of the head. Hip extension was achieved by placing two columns of pillows under the legs (Figure 2).

\section{Statistical Methods}

Measurements from the four time points (i.e. preoperative, after patient positioning, after balloon inflation and postoperative) were tabulated and statistical analysis was performed using SPSS (SPSS, Inc., Chicago, IL). Paired sample t-test was used to statistically evaluate changes in Cobb angles, wedge angle and vertebral heights. A $P$ value $<0.05$ was accepted to demonstrate statistical significance.

\section{Results}

The average interval between original fracture radiographs to PBK was 15.9 days. The extent of anterior vertebral collapse averaged $31.7 \%$ of the original height (range, 10.5 to $98.3 \%$ ). The described postural reduction technique reduced the collapse to $24.7 \%$ of the original anterior vertebral body height $(\mathrm{P}=0.15)$ (Table 2). A measurable increase in anterior vertebral height was achieved in $57.1 \%$ of VCFs upon patient positioning $(n=12)$. Posteriorly, the mean vertebral height collapse was $4.3 \%$ of the original height (range: 0 to $29.6 \%$ ). The positioning technique was able to restore posterior vertebral height to $99 \%$ of the origi-

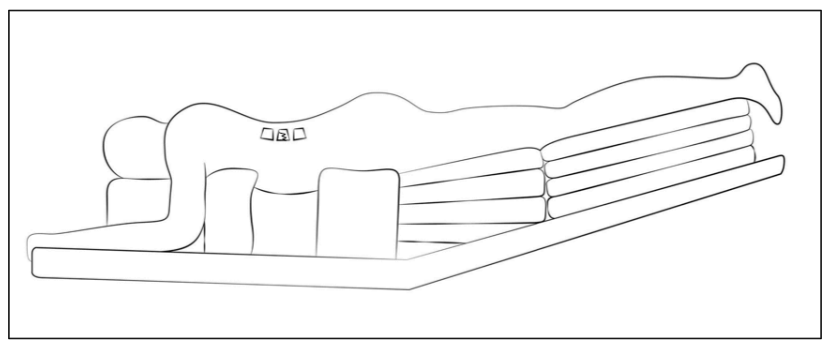

Fig. 2. Schematic representation of the Reverse Thomas Position. 
nal height $(P=0.01)$ (Figure 3). Upon inflation of balloon tamp, the anterior body height restored to $82.3 \%$ of the original height and the posterior was shown to have full restoration of original height $(100 \%)$.

In terms of the sagittal configuration of the spine, the average wedge angle was $15.8^{\circ}$ (range: $3.8^{\circ}$ to $36.3^{\circ}$ )

Table 2. Comparisons of sagittal configuration pre and post positioning.

\begin{tabular}{|c|c|c|c|}
\hline & Mean & $\begin{array}{r}P \\
\text { Value }\end{array}$ & $\begin{array}{r}\text { Confidence Inter- } \\
\text { val (CI) }\end{array}$ \\
\hline $\begin{array}{l}\text { Anterior Height (Post - pre } \\
\text { positioning) }\end{array}$ & $\begin{array}{r}0.07 \text { of original } \\
\text { height }\end{array}$ & 0.15 & -0.28 to 0.17 \\
\hline $\begin{array}{l}\text { Posterior Height } \\
\text { (Post }- \text { pre positioning) }\end{array}$ & $\begin{array}{r}0.04 \text { of original } \\
\text { height }\end{array}$ & 0.014 & 0.009 to 0.07 \\
\hline $\begin{array}{l}\text { Wedge Angle } \\
\text { (Post - pre positioning) }\end{array}$ & $3.6^{\circ}$ & 0.002 & 1.5 to 5.7 \\
\hline $\begin{array}{l}\text { Kyphosis Angle (Post - pre } \\
\text { positioning) }\end{array}$ & $4.7^{\circ}$ & 0.004 & 1.6 to 7.09 \\
\hline
\end{tabular}

and average kyphosis angle (Cobb angle) was $5.6^{\circ}$ (range: $-5.4^{\circ}$ to $24.2^{\circ}$ ) preoperatively. Placement of the patient in a hyperlordotic position resulted in a significant spontaneous reduction in deformity by $3.6^{\circ}$ wedge vertebral angle $(\mathrm{P}=0.002)$ and $4.7^{\circ} \mathrm{Cobb}$ angle $(\mathrm{P}=0.004)$ to $12.2^{\circ}$ and $0.9^{\circ}$, respectively. An improvement of Cobb angle of at least $5^{\circ}$ was seen in approximately one-third of cases $(38.1 \%, \mathrm{n}=8)$. Inflation of balloon tamp further decreased the wedge angle by $0.9^{\circ}$ and improved the Cobb angle by another $0.1^{\circ}$ (Figure 3 ).

While vertebral height and sagittal configuration of the spine were improved intra-operatively, it appeared that vertebral height, kyphosis angle and wedge vertebral angle were not maintained at a mean follow up of 8.6 months (Figure 3). Compared with the preoperative radiographs, PBK improved overall vertebral heights and wedge vertebral angle. However, a greater degree of kyphosis was noted, as demon-

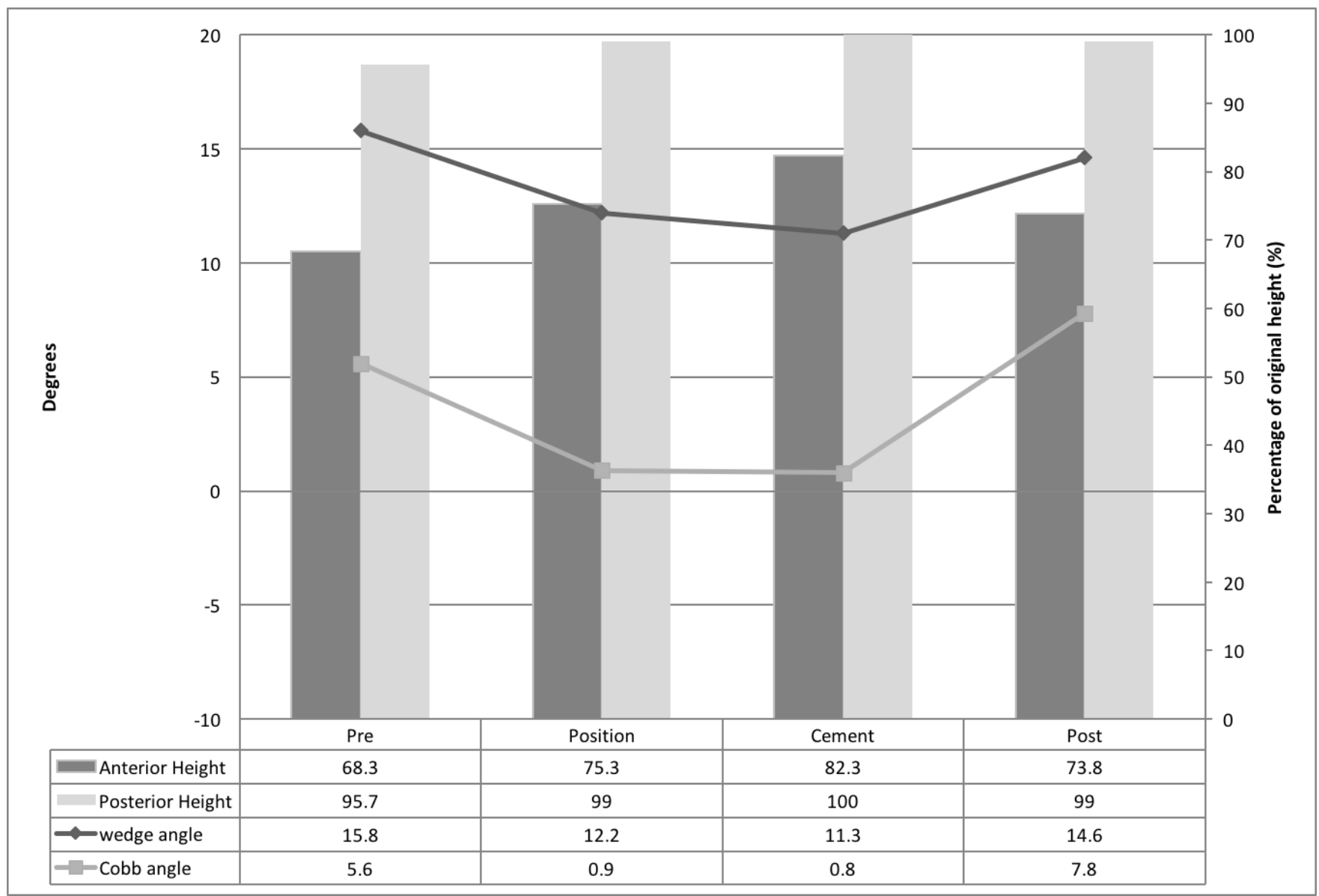

Fig. 3. Changes in anterior and posterior height, and wedge and kyphosis (Cobb) angles preoperative, intraoperatively and postoperatively. A positive Cobb angle denotes an overall kyphosis and negative denotes an overall lordosis of the lumbar spine. 
strated by an average Cobb angle of $5.6^{\circ}$ from $7.8^{\circ}$ preoperatively.

\section{Discussion}

In $\mathrm{VCF}$, the existence of corticocancellous disruption and subsequent intravertebral cleft give rise to the dynamic mobility of the fracture,${ }^{4}$ which permits vertebral height restoration upon postural reduction and balloon inflation. Previous studies have described many techniques for postural correction of vertebral body dimensions..$^{4,8,911,12}$ However, these were all based on the principle of hyperextension of the affected segment of spine. As the anterior longitudinal ligament (ALL) is adherent to the upper and lower edges of the vertebral body, and to the intervertebral disc, tension across the ligament results in expansion of the collapse intravertebral cleft. Cawley et al expanded on this principle and suggested that additional hip extension further increases the degree of ligamentotaxis and subsequent restoration of vertebral dimensions. ${ }^{10}$ As the ALL terminates at the sacral promontory, by anteverting the pelvis and increasing the lumbosacral angle, the sacrum acts as a fulcrum over which further traction of the longitudinal fibres of the ALL can be achieved in addition to lumbar hyperlordosis (Figure 4). While this technique was shown to be effective, the results were limited by a heterogeneous patient population. Only $64.3 \%$ of fractures in their study were at the thoracolumbar junction. This segment of spine bears the greatest dynamic load and is therefore highly mobile, making it the most amenable to postural reduction. In view of this, our study evaluated the efficacy of this postural reduction technique in VCFs at specifically the thoracolumbar junction.

The results of the present study confirmed that placing patient in hyperlordotic position with pelvic extension was useful for restoring vertebral height and correcting kyphosis in VCFs at the thoracolumbar junction. In addition, it was demonstrated that both patient positioning and inflation of balloon contributed similarly to the overall reduction achieved, with patient positioning being slightly more effective at improving the Cobb and wedge angle. Lieberman et al. reported measurable end-plate elevation in $48 \%$ of VCFs in their series, which they ascribed to the balloon tamp intervention. ${ }^{1}$ Similarly, McKiernan et al. documented improvement in vertebral height in $35 \%$ of VCFs from vertebroplasty. ${ }^{4}$ In our series, measurable increase in anterior vertebral height was found in $57.1 \%$ of VCFs upon patient positioning. After inflation of balloon, this increased to $82.3 \%$. A remarkably similar result has been reported by Hiwatashi et al (84.7\%), although they ascribed the height restoration to the injection of cement. When comparing our results with those reported in previous studies, one must acknowledge two important issues. Firstly, the efficacy of the intervention performed is strongly dependent on the level of VCF. As mobile fractures dominate at the thoracolumbar junction, and this is the property that has been described to permit vertebral height restoration, ${ }^{4}$ a degree of selection bias must be taken into account when interpreting our results. Secondly, direct comparison to previously described positioning tech-

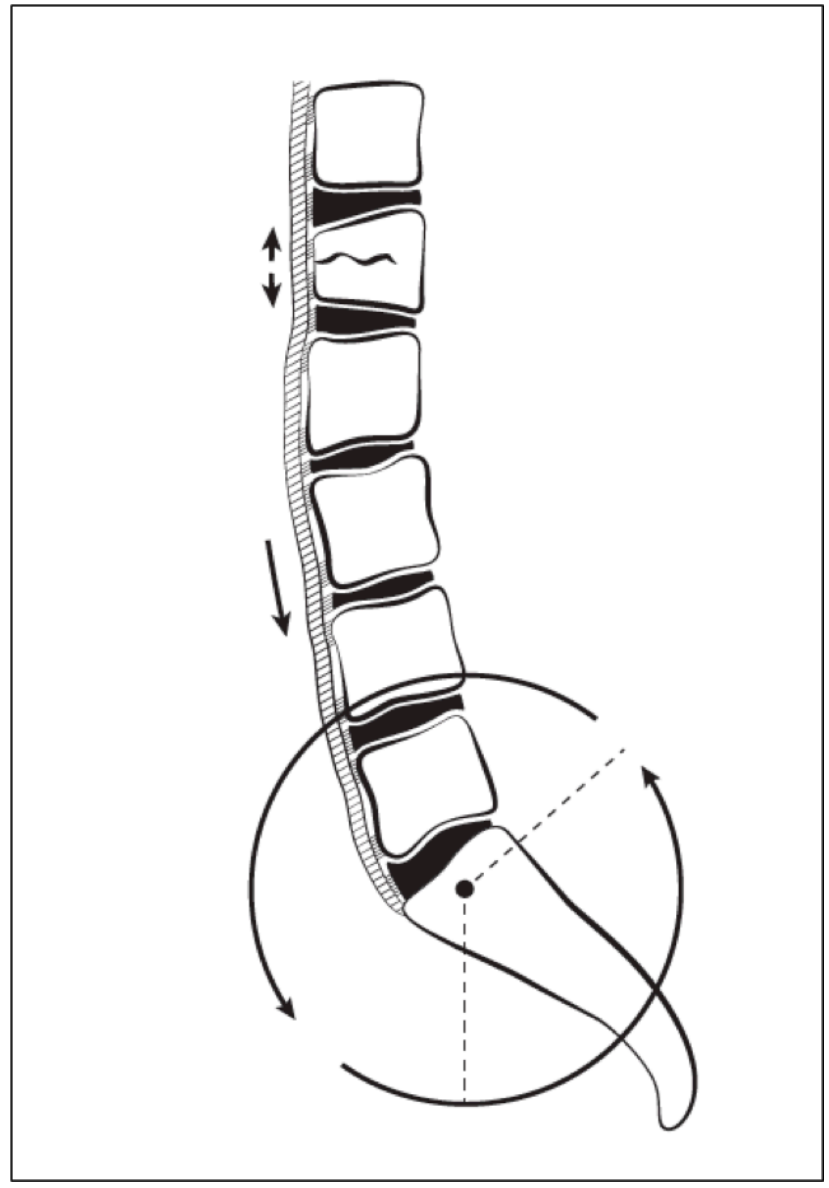

Fig. 4. Schematic representation of the additional ligamentotaxis of the anterior longitudinal ligament (ALL) achieved by pelvic anteversion. Note the attachment of the ALL to the intervertebral discs, sacral promontory, and the upper and lower edges of each vertebral body, allowing for distraction across fracture site. 
niques is often not possible, as the most studies only reported vertebral dimensions pre- and postoperatively, and did not measure the relative contribution of each step of the intervention to the final sagittal dimensions. A study by Voggenreiter et al. was one of the few studies that assessed this. ${ }^{5}$ Their postural reduction technique involved positioning the patient prone with the spine extended by chest and pelvic bolsters. Their series of 39 VCFs demonstrated similar results in sagittal correction, with an improvement in Cobb and wedge angle of $6.4^{\circ}$ and $3.7^{\circ}$, respectively ( $4.7^{\circ}$ and $3.6^{\circ}$ in our series).

Despite the improvement of the sagittal alignment and height restoration, we found a substantial loss of correction of $7.0^{\circ} \mathrm{Cobb}$ angle from the final intraoperative radiograph to the most recent standing lateral radiograph. Similarly, loss of anterior height of $8.5 \%$ of original height was also noted. The progression of kyphosis is difficult to interpret as deterioration of the underlying disease like osteoposrosis also leads to further kyphotic deformity. Another explanation for this is the presence of persistent dynamic mobility in the intervertebral disc space. ${ }^{5}$ Previous studies have also suggested that fixation of microfractures in the vertebra may be less stable in PBK compared to vertebroplasty due to a lower cement injection pressure, which results in less diffuse spreading of cement, especially into the pre-existent cracks and spaces within the vertebral body. ${ }^{13} \mathrm{~A}$ study with more patients and longer follow-up duration is warranted to determine the maintenance of sagittal alignment and vertebral height post-PBK.

While our study demonstrated promising results for this postural reduction technique, there were some limitations to the study design. The relatively small numbers of patients and compression fractures limited statistical analysis of some observations. Moreover, fracture morphology (wedge, crush, or biconcave) and fracture reparative activity (demonstrated by presence of oedema on $\mathrm{T} 2$ weighted chemical fat suppression or short tau inversion recovery on MRI) was not classified in our study. In addition, due to the nature of the procedure, it was not possible to blind interpreters to pre- and post-op observations. Specific landmarks and comparisons of the measurements taken by the 3 interpreters were performed to reduce any element of measurement bias. As this is not a controlled trial comparing patients with hyperextension at hip and without; the confidence with which the positioning technique can be recommended is low. Further well-conducted randomised controlled trials are warranted to assess the true efficacy of this positioning technique.

While it is believed that correction of sagittal misalignment and postural deficit improves the overall outcome of the patient, this assumption remains unproven and requires further critical analysis. Nevertheless, the described postural reduction technique is able to reduce the risk of kyphosis and its related morbidities in the short term.

\section{Conclusion}

In conclusion, we demonstrated an average Cobb and wedge angle improvement of $4.7^{\circ}$ and $3.6^{\circ}$ from the reverse Thomas position, creating a $7.8 \%$ increase in the anterior vertebral height. Based on these results, we confirm that pelvic anteversion in addition to hyperextension of the lumbar spine maximise ligamentotaxis of the ALL, thereby correcting sagittal alignment.

\section{Acknowledgements}

The authors thank Aurora Adkins for her contribution in the graphic design.

\section{References}

1. Lieberman IH, Dudeney S, Reinhardt MK, Bell G. Initial outcome and efficacy of "kyphoplasty" in the treatment of painful osteoporotic vertebral compression fractures. Spine (Phila Pa 1976). 2001; 26(14):1631-1638.

2. Wardlaw D, Cummings SR, Van Meirhaeghe J, Bastian L, Tillman JB, Ranstam J, Eastell R, Shabe P, Talmadge K, Boonen S. Efficacy and safety of balloon kyphoplasty compared with nonsurgical care for vertebral compression fracture (Free): A randomised controlled trial. Lancet. 2009; 373(9668):1016-1024. 3. Klazen CA, Lohle PN, de Vries J, et al. Vertebroplasty versus conservative treatment in acute osteo- 
porotic vertebral compression fractures (Vertos II):

An openlabel randomised trial. Lancet. 2010; 376(9746):1085-1092.

4. McKiernan F, Jensen R, Faciszewski T. The Dynamic Mobility of Vertebral Compression Fractures.

J Bone Miner Res. 2003; 18(1):24-29.

5. Voggenreiter G. Balloon kyphoplasty is effective in deformity correction of osteoporotic vertebral compression fractures. Spine. 2005; 30(24):

2806-2812.

6. Faciszewski T, McKiernan F. Calling all vertebral fractures, classification of vertebral compression fractures: a consensus for comparison of treatment and outcome. J Bone Miner Res. 2002; 17(2):185191.

7. Siemionow K, Lieberman IH. Vertebral augmentation in osteoporosis and bone metastasis. Curr Opin Support Palliat Care. 2007; 1(4):323-327.

8. Teng MM, Wei CJ, Wei LC, Luo CB, Lirng JF, Chang FC, Liu CL, Chang CY. Kyphosis correction and height restoration effects of percutaneous vertebroplasty. AJNR Am J Neuroradiol. 2003;24(9):1893-1900.

9. Masala S, Masala S, Fiori R, Massari F, Postorino M, Simonetti G. Percutaneous kyphoplasty: indications and technique in the treatment of vertebral fractures from myeloma. Tumori. 2004; 90(1):22-26.

10. Cawley DT, Sexton P, Murphy T, McCabe JP. Optimal patient positioning for ligamentotaxis during balloon kyphoplasty of the thoracolumbar and lum- bar spine. Journal of Clinical Neuroscience. 2011; 18(6):834-836

11. Shin JJ, Chin DK, Yoon YS. Percutaneous vertebroplasty for the treatment of osteoporotic burst fractures. Acta Neurochir. 2009; 151(2):141-148. 12. Kim HS, Ju CI, Kim SW, Lee SM, Shin H. Balloon kyphoplasty in severe osteoporotic compression fracture: is it a contraindication? Neurosurgery. 2007;60:1-6.

13. Hiwatashi A, Moritani T, Numaguchi Y, Westesson PL. Increase in Vertebral Body Height after Vertebroplasty. AJNR Am J Neuroradiol. 2003; 24(2):185-189.

\section{Disclosures \& COI}

All authors report no disclosures or conflicts of interest.

\section{Corresponding Author}

Jonathan P Ng MRCSI, Department of Orthopaedic and Traumatology, Galway University Hospital, Republic of Ireland.ngjp2606@gmail.com.

Published 18 May 2016.

This manuscript is generously published free of charge by ISASS, the International Society for the Advancement of Spine Surgery. Copyright @ 2016 ISASS. To see more or order reprints or permissions, see http://ijssurgery.com. 